\title{
A IDENTIDADE NACIONAL NA ERA DA GLOBALIZAÇÃO
}

\author{
Rócio Stefson Neiva Barreto ${ }^{1}$
}

\begin{abstract}
Resumo
A idéia de que o avanço dos mecanismos de globalização um dia terminará por dissolver todas as fronteiras culturais e identitárias culminando na emergência de uma "identidade global" tornou-se bastante difundida nos últimos tempos. Entretanto, o surgimento de movimentos nacionalistas vinculados à afirmação de uma identidade local convida à problematização desta concepção, revelando um quadro aparentemente paradoxal, no qual os próprios mecanismos de globalização despontam ao surgimento destes movimentos. Este artigo tem por objetivo o estudo deste paradoxo, a partir da identificação de elementos presentes no fenômeno da globalização que viabilizam e mesmo incitam tais movimentos. Outro ponto investigado remete à própria possibilidade de consolidação de uma "identidade global", uma vez que a própria conceituação de "identidade" supõe alteridade, ao contrário de homogeneização.
\end{abstract}

\section{Palavras-chave}

Globalização; Identidade Nacional; Identidade Global; Nacionalismo.

\section{Abstract}

The conception that the advancement of the mechanisms of globalization some day will dissolve all cultural and identity frontiers, culminating in the apparition of a "global identity" became very popular lately. However, the emergence of nationalist movements linked to the assertion of local identity calls for the problematization of this design, revealing a seemingly paradoxical, in which the mechanisms of globalization to the emergence of these movements emerge. The purpose of this article is to investigate this paradox, considering the globalizations elements that became possible - and even incite - these movements. Another investigated point it's the possibility of consolidation of a "global identity", since the very concept of "identity" presupposes alterity, unlike homogenization.

1 Rócio Stefson Neiva Barreto é bacharelando em Ciências Sociais na Universidade Federal de Minas Gerais. 
Keywords

Globalization; National Identity; Global Identity; Nationalism.

\section{Introdução}

A proposta deste estudo é a de tecer algumas reflexões sobre a identidade nacional em tempos de globalização. Neste sentido, a principal questão que norteia este texto versa sobre as possibilidades de consolidação de uma identidade nacional em um contexto onde as barreiras culturais, econômicas e políticas tornam-se cada vez mais fluidas - o que, à primeira vista, parece indicar uma tendência jamais vista de "homogeneização cultural" e de "identidade global" em escala planetária. Contudo, a emergência de conflitos e a existência de resistências frente a esta homogeneização - por exemplo, as recentes reações xenófobas na Europa aos imigrantes e mesmo a atual política de imigração restrita dos Estados Unidos, somadas aos movimentos de resistência às recentes invasões americanas no Iraque, dentre outros casos - representam um convite para a problematização do alcance do poder de homogeneização constantemente referido à globalização. Nestes termos, como equacionar os desdobramentos da globalização com o advento de movimentos nacionalistas? É possível pensar que os próprios efeitos da globalização podem favorecer a consolidação de identidades nacionais? Se a resposta for positiva, que mecanismos estariam por detrás deste aparente paradoxo? Caso contrário, quais seriam as condições necessárias para a formação de uma identidade global, ou seja, uma identidade compartilhada por todos os povos, capaz de neutralizar as suas diferenças?

Desta maneira, o propósito deste texto é o de - ainda que não seja o de oferecer respostas definitivas a tais questões - oferecer ao leitor alguns subsídios teóricos que propiciem a reflexão acerca desta problemática, superando a concepção de que a globalização terminaria por abolir as fronteiras culturais, sociais e econômicas que delineiam a identidade nacional, em favor de uma "comunidade global" com uma "identidade global". De fato, as hipóteses básicas deste estudo são as de que os próprios mecanismos da globalização convidam à emergência das identidades nacionais, e que a própria concepção de identidade anula a possibilidade de emergência de uma identidade global. Mas, como se dão este convite e esta anulação? 


\section{Metodologia}

Uma vez que este estudo se destina a esclarecer questões referentes às relações entre a globalização e a insurgência de identidades nacionais, esta pesquisa se coloca como exploratória. Desta forma, trata-se de uma pesquisa que visa, através da coleta de informações sobre determinado assunto, desenvolver, modificar e esclarecer idéias e conceitos que sirvam de subsídios para estudos posteriores, através de hipóteses pesquisáveis (Selltiz et al, 1967).

A fim de dar conta deste estudo exploratório, o método privilegiado desta pesquisa é o levantamento bibliográfico, através da leitura e análise de textos, livros e artigos concernentes à temática abordada. Neste sentido, buscou-se aqui verificar pontos de interseção nos materiais levantados que pudessem subsidiar a exploração das hipóteses levantadas - no caso, a de que a globalização, se por um lado pode ser entendida como um vetor de homogeneização cultural capaz de suplantar as identidades nacionais, por outro lado também pode promover a insurgência de movimentos de afirmação desta mesma identidade, a partir de desdobramentos de seus próprios mecanismos de operacionalização; e a de que a própria concepção de identidade global revela-se paradoxal e contraditória.

\section{Globalização: uma dialética entre o local e o global}

Muitos situam a era da Globalização - com seus infindáveis avanços tecnológicos, com sua capacidade de comunicação em massa em tempo real sem precedentes, com seu incrível fluxo de informações e circunscrita ao desenvolvimento do capitalismo neoliberal - em uma posição de antagonismo em relação ao advento e mesmo à manutenção da identidade nacional ou do nacionalismo - dos nacionalismos, talvez fosse melhor acrescentar ${ }^{2}$.

\footnotetext{
${ }^{2}$ Guibernau (1997) menciona duas categorias básicas de nacionalismos: o das "nações sem estado" e o de Estado. Neste último caso, o Estado se vale de seu poder para homogeneizar de sua população. Nisto se enquadram os dispositivos educacionais estatais, o controle dos meios de comunicação, o monopólio juridicamente legitimado do estado sobre a violência etc. Devemos atentar para as múltiplas formas destes nacionalismos de Estado. Ora este pode se dar através de um caráter explicitamente autoritário, ora por um caráter assistencialista - e mesmo estes podem muitas vezes ser enquadrados
} 
É possível compreender esta posição ao considerarmos como a globalização é constantemente definida mediante um mecanismo de "dissolução de fronteiras", atravessado pelo livre (sic) fluxo de pessoas, de serviços, de mercadorias ${ }^{3}$, pela limitação da intervenção estatal em favor da "mão invisível" do livre comércio e dos interesses das grandes corporações transnacionais, e mesmo pelo enfraquecimento de barreiras culturais - que no contemporâneo se encontra bastante facilitado pela difusão da Internet. Alguns tendem mesmo a enxergar neste processo os primeiros passos para surgimento de uma "cultura globalizada", em grande parte em função das novas tecnologias da comunicação de massa de alcance planetário. Neste contexto, Giddens pensa a globalização como "a intensificação das relações sociais no mundo inteiro, que liga localidades distantes de tal modo que os acontecimentos de uma região são formados por eventos que ocorrem a milhares de distância e vice-versa" (Giddens, s/d, apud Guibernau, 1997, p. 139), levando Guibernau a concluir que:

Espaço e tempo são redefinidos. As percepções dos limites físicos do espaço são alteradas. O tempo requerido para produzir e processar a informação foi a tal ponto reduzido que já podemos perceber um hiato dramático entre aquele $\mathrm{e}$ outras experiências humanas com o tempo. A globalização implica a possibilidade de se referir à "sociedade humana", algo que nunca existiu antes, no sentido de que, agora, todos os possíveis atores estão no palco simultaneamente. (Guibernau, 1997, p.139)

Não se pode esquecer também, como parte deste processo, a emergência dos grandes blocos econômicos e políticos - constituído por diversos estados nacionais - e a consolidação de organizações internacionais e supranacionais de planejamento político, econômico e também social e cultural (nos quais podemos situar a Organização das Nações Unidas (ONU), a Organização das Nações Unidas para a

naquilo que se costuma designar por "populismo". Alertamos também para a possibilidade de graus intermediários entre ambos os nacionalismos de Estado. Não nos faltam exemplos em todos estes casos.

3 Basta considerar as facilidades trazidas pela Internet, especialmente em relação à compra de bens e até de serviços em praticamente qualquer lugar do planeta. 
Educação, a Ciência e a Cultura (UNESCO) e mesmo os Direitos Humanos, que se pretendem universais, isto é, globais ${ }^{4}$.

Comumente, fala-se de uma espécie de "imperialismo cultural", que viria operando desde o colonialismo inicialmente liderado pela Espanha, Portugal e Inglaterra, tendo largamente se pulverizado no chamado período neo-imperialista e que, após a Segunda Grande Guerra e a queda da URSS, estaria solidificando a imposição da cultura ocidental ao resto do mundo. De fato, de acordo com Guibernau (1997), o alcance e a posição de cada cultura expressam o poder que a nação possuidora desta cultura possui no contexto global. Deste modo,

Como as dominações de gênero e etnia, o imperialismo cultural é uma violência simbólica que se apóia numa relação de comunicação coercitiva para extorquir a submissão e cuja particularidade consiste, nesse caso, no fato de universalizar particularismos vinculados a uma experiência histórica singular, ao fazer com que sejam desconhecidos, enquanto tal, e reconhecidos como universais. (Bourdieu; Wacquant, 2001)

Em contrapartida, as culturas agredidas pelo racismo cultural assumem uma identidade defensiva, o que normalmente é feito com o objetivo de retomar a identificação com suas culturas de origem. Essa cultura de contrapartida, então, estabelece uma cultura de afirmação das diferenças, da alteridade, manifestando um posicionamento político bem claro objetivando a superação das desigualdades advindas das diferenças. 0 que faz alguns autores concordarem que, atualmente, a posição máxima na hierarquia de difusão cultural é ocupada pelos EUA,

${ }^{4}$ Embora não seja este o foco, a problemática em torno dos direitos humanos ilustra bem o problema. Não podemos esquecer que os Direitos Humanos soam como uma imposição de valores a muitos povos e culturas, que têm então algumas de suas práticas vedadas em nome deste pretenso universalismo. De fato, a imposição de direitos universais fere a noção de "relativismo cultural" tão em voga, que acaba se revelando limitada. Mesmo a idéia de democracia, apregoada por Guibernau (1997) e Appiah (1999) como a melhor forma de se constituir uma espécie de nacionalismo "benfazejo" e pacífico, essencialmente cosmopolita e respeitador da alteridade, parece sucumbir a este problema. A democracia se referencia por seus contornos ocidentais, e quando levamos o relativismo cultural ao limite, percebemos que pode se constituir numa imposição mal-quista, especialmente quando firmemente associada ao capitalismo neoliberal e suas práticas de "intervenção humanitária". 
que ao consolidar-se como a maior potência mundial, importa também com a força de sua indústria mass media o "american way of life", um "modo de vida" baseado no consumismo, próprio ao florescimento do neoliberalismo (Canclini, 1997). Pela lógica própria do sistema neoliberal e pelos desdobramentos da globalização, todos os povos e nações estariam sujeitos a este quadro, no qual deveriam aquiescer sob o risco de submergir. A tendência, portanto, seria a criação de uma cultura global, homogênea, uma padronização dos modos de vida em todos os cantos do mundo, que eliminaria gradualmente as diferenças entre todos os povos. Como situar então o lugar do nacionalismo neste contexto?

Desta maneira, o mecanismo se revela mais complexo. 0 fenômeno da globalização não pode ser compreendido como mero antagonista da emergência dos nacionalismos, ou da afirmação de uma identidade nacional - isto é, cultural. De fato, podemos analisar a questão através um outro ponto de vista, no qual a globalização compete justamente para a emergência e afirmação de culturas nacionais, ou em muitos casos, para a afirmação de "nações sem estado", categoria na qual podemos circunscrever todos os povos ${ }^{5}$ que, ao localizarem-se em determinado território delimitado, não são - ou não se percebem efetivamente representados pela figura do Estado, constituindo minorias ou não -para o qual um dos exemplos mais representativos seria o conflito árabe-israelense, ou a questão do povo curdo no Oriente Médio. Nestes casos, podemos falar, como sugere Guibernau (1997), em uma política de preservação da identidade nacional, que se constitui

\footnotetext{
5 Talvez a melhor expressão a ser utilizada aqui seja a de "comunidade imaginada", como nos sugere Anderson (1989), no lugar de "povos". Por comunidade imaginada Anderson entende comunidade que se pretende soberana e limitada, na medida em que exclui outras "comunidades imaginadas" a fim de preservar sua singularidade e, portanto, sua identidade. É uma nação que se constitui em uma suposta unidade, que ganha corpo através da percepção da existência de semelhantes, que partilham a mesma língua, os mesmos ritos, tradições etc. Esta comunidade é imaginada, principalmente em função de estes semelhantes não possuírem uma implicação concreta nas vidas uns dos outros; neste sentido, podemos dizer que se trataria basicamente de uma abstração.
} 
como uma tentativa de resistência frente à homogeneização global suscitada pela Globalização ${ }^{6}$.

Tratemos, portanto, de precisar esta homogeneização suposta pela globalização. De acordo com Guibernau (1997), a globalização é intrínseca à "dialética do local e do global", um processo no qual tanto o local e o global conjugam-se simultaneamente, estabelecendo novas configurações na medida em que cada um dos opostos absorve ou se deixa absorver pelo outro. Desta forma, o local e global formam um todo dialético e dinâmico, no qual cada momento reconfigura a unidade. Ora o local captura o global, ora o global captura o local, ora ambos se entrelaçam em diferentes níveis. Como exemplo, Guibernau (1997) cita a apropriação que o fundamentalismo islâmico faz das tecnologias e dos meios de comunicação de massa para divulgar suas mensagens e assim, constituir um foco de resistência em relação à homogeneização cultural supostamente promovida pelo Ocidente. Deste modo, apesar de se apresentar como um movimento de oposição ao mundo ocidental, e por extensão, à globalização, o fundamentalismo islâmico termina por se valer dos desdobramentos desta. 0 "terrorismo" em escala planetária, ou a possibilidade de intervenção em escala planetária, também reforça esta posição.

\section{As crises da modernidade}

Estes aparentes paradoxos indicam, de acordo com Guibernau (1997), uma "crise da modernidade" que se encontra profundamente vinculada ao advento dos nacionalismos e movimentos de afirmação das identidades nacionais. Esta crise engloba desde os avanços tecnocientíficos - especialmente os relacionados à informação e, consequentemente, aos meios de comunicação de massa de escala planetária, os quais detidos especialmente pelo Ocidente possibilitam a expansão de seus valores, estilos de vida e idéias em escala global - que impulsionam drásticas transformações, assim como constantes mudanças paradigmáticas nas ciências, no conhecimento e nos valores. A crise abarca também a economia neoliberal, culminando numa dependência entre as nações que impossibilita certezas e limita perspectivas, uma vez que nenhuma decisão pode ser tomada sem considerar o contexto internacional.

6 Importante mencionar que esta "política de identidade nacional" pode também abarcar outras espécies de nacionalismos, além daqueles que se referem a uma minoria que se percebe oprimida. 
Em uma época onde não existem mais certezas, na qual os avanços tecnológicos não são passíveis de acompanhamento, em que a todo o momento ocorrem novas transformações, passa a existir justamente uma demanda por referências, por pontos de balizamento que sirvam para estabelecer um sentimento de identidade e vieses para organização da existência e significação do mundo. É neste sentido que o sentimento de pertença a uma comunidade, ou a uma nação se insere. o nacionalismo passa a ser um recurso de enfrentamento diante deste caos imprevisível, desta expropriação cultural que se encontra em grande medida associada ao movimento de globalização. Assim, temos uma espécie de dialética na qual aquilo que se contrapõe ao local é justamente aquilo que confere a possibilidade de emergência de uma demanda por identidade nacional, na medida em que esvazia o mundo de certezas ao mesmo tempo em que o fragmenta de várias formas. Em outros termos, por este viés podemos concluir que é a própria globalização que favorece o advento dos nacionalismos. Assim, podemos entender esta crise, aparentemente antagônica e obstruidora destes movimentos, como justamente um dos fatores que lhes alimentam.

Vattimo (2000) percebe duas modalidades deste retorno: uma se pode observar na cultura mais palpável e estaria relacionada com as condições globais pós Segunda Grande Guerra. Alude à ansiedade em relação a catástrofes planetárias, tais como o receio da multiplicação de armas nucleares, ameaças sobre a ecologia planetária e até mesmo questões ligadas à manipulação genética, que levam a sociedade a se questionar sobre uma "natureza humana". Vattimo (2000) vai mais longe e supõe que o desenvolvimento do capitalismo e a emergência do neoliberalismo também geram uma ansiedade decorrente da perda do sentido da existência, "do verdadeiro tédio que parece acompanhar inevitavelmente o consumismo" (Vattimo, 2000, p. 93), que em sua incrível rotatividade em função do surgimento de novas mercadorias, não é capaz de suprir certas demandas humanas de caráter nãomercantil. Pondera ainda que o "retorno do religioso" poderia ser enquadrado numa espécie de auto-determinismo dos povos na medida em que a expressão religiosa pode ser utilizada para legitimar uma identidade local, étnica ou tribal, consistindo uma recusa da modernização na proporção em que esta destrói raízes autênticas da existência.

A noção de uma democracia globalizada é de suma complexidade à interconectividade mundial. Isso torna possível o reconhecimento de certas questões e políticas como apropriadas a governos locais e 
Estadas Nacionais; mas também identifica outras questões como especificas de algumas regiões, e além destas, reconhece outras que precisam ser tratadas por novas instituições (como é o caso da identidade nacional, meio ambiente, segurança global etc.). Esses arranjos políticos não são apenas necessários, como uma possibilidade ante as transformações sem limites, ambivalentes e de extrema liquidez pelos quais vivem os processos regionais e globais.

A ameaça da máquina, da mesma forma como sugere Vattimo, ao promover a expropriação, o "arrancar das raízes" é aquilo contra o qual a religião se encontra em conflito (como tentativa de ligar-se ao próprio, ao solo, ao idioma, à cultura, à nação) e que por isso, lhe confere um lugar. Em outras palavras, a ameaça de perda pode, neste sentido, promover o apego às raízes, e alimentar a força simbólica da religião, da etnia, da terra, dos valores e da nação.

É neste contexto que os valores do fundamentalismo islâmico, de acordo com Guibernau,

(...) permitem o reestabelecimento de um senso de identidade e dignidade que se origina dentro de sua própria cultura. A vergonha do atraso, quando comparado com os países desenvolvidos do Ocidente é substituída pelo orgulho e convicção de que a doutrina da fé pode regenerar a comunidade (...). (Guibernau, 1997, p.148)

Um outro sintoma que pode ser apontado como decorrência desta "crise" é a existências de determinadas demandas de controle do estado nacional. Assim, apesar das organizações de controle internacional que monitoram os estados nacionais, é possível falar numa autenticidade do estado nacional que lhe proporciona uma relativa autonomia. Tomemos como exemplo o caso da União Européia (UE). De acordo com Mann (2000), a legislação da UE - que a princípio apenas teria sido suplementar à legislação nacional dos países membros - terminou por servir de padrão para estas legislações nacionais, o que leva muitos governos a revisarem constantemente suas leis. Somem-se a isso o mercado único europeu e a padronização da moeda7. Apesar destes fatores, a UE não parece, para o autor, ser capaz de sufocar a força dos estados nacionais europeus, uma vez que todas estas medidas dizem respeito mais restritamente ao planejamento econômico. A política

7 Ainda que a padronização monetária encontrasse ampla resistência, especialmente por parte da Inglaterra. 
cotidiana destes países pouco é afetada pelas normas da UE. De fato, o autor aponta para uma certa ausência de interesse pela UE em relação aos aspectos mais propriamente sociais - a UE não está comprometida com um movimento de cidadania ou identidade européia. As políticas nacionais que dizem respeito a questões não abarcadas pela UE - como impostos, políticas de renda, medidas assistenciais, questões morais etc - competem aos partidos políticos nacionais. Como mais um fator que demonstra que a UE não suplantou os estados nacionais europeus, 0 autor aponta também para a ausência de um exército europeu.

Ao levarmos em conta a tendência de consolidação, dentro da UE, de políticas rígidas de controle imigratório, temos mais um indício de resistência às conseqüências da globalização, na medida em que esta também se define pela "livre" circulação de pessoas. Guibernau (1997) relaciona este movimento com um redimensionamento da identidade européia, que culmina no engendramento de um nacionalismo supranacional, uma vez que, para o autor, a identidade nacional também se define pela oposição a um "outro", ou seja, àqueles que são considerados estranhos por não partilharem os mesmos hábitos, culturas e raízes étnicas ${ }^{8}$ da comunidade local. É preciso considerar também que esta tendência de resistência ao "outro" pautada na ampliação do rigor das políticas de controle de imigração e de concessão de cidadania européia se vincula especialmente a fatores de natureza sócio-econômica, como o aumento do desemprego na Europa, potencializado pelos fluxos de imigração. Neste sentido, o autor coloca que:

A União Européia, se prosperar, certamente desenvolverá uma nova qualidade de nacionalismo que não apagará a identidade local. Tal nacionalismo será invocado sempre que a ação comum for necessária na arena econômica, social ou política, para combater um inimigo comum ou defender a prosperidade da União. 0 desejo de

\footnotetext{
8 Vale lembrar as atuais políticas de aculturação que alguns países europeus têm desenvolvido em relação às exigências destinadas àqueles que buscam cidadania européia. A Alemanha, por exemplo, adotou recentemente uma medida que inclui a aplicação de uma prova acerca de conhecimentos em relação à economia, política, história e cultura alemãs para os aspirantes à cidadania alemã. 0 atual presidente da França, Nicolas Sarcozy, também defende medidas semelhantes. A aprovação, no parlamento europeu, de medidas que facilitam a deportação de imigrantes ilegais - ou seja, dos outros - é sintomática deste processo.
} 
suspender a imigração de países pobres para a Europa contém as sementes da conseqüente solidariedade entre parceiros europeus e pode finalmente favorecer o advento deste nacionalismo supranacional. 0 discurso político do nacionalismo supranacional ignorará a estrutura de classes e será dirigido ao cidadão europeu comum, como se tal categoria existisse acima de outras fontes de identidade e determinasse certo status partilhado por todos os membros individuais. As questões críticas, nessa instância, serão as de como moldar uma identidade especificamente européia e que grupos serão considerados "estrangeiros". (Guibernau, 1997, p. 160)

Desta maneira, observa-se que além da angústia gerada pela ausência de certezas desdobrada pela globalização, uma outra conseqüência da mesma - a ampliação da circulação de pessoas em escala planetária também repercute gerando movimentos de afirmação das identidades nacionais, especialmente na forma de controle dos fluxos migratórios nos países desenvolvidos. Mas será que apenas estes elementos diretamente relacionados à globalização obstruem a insurgência de uma "identidade global", ou existiriam ainda outros fatores vinculados mais propriamente às condições para a formação de uma identidade nacional que impediriam seu surgimento?

\section{Identidade Global e Identidade Nacional}

Guibernau (1997) relaciona as atuais insurgências nacionalistas - ou seja, o sentimento de pertença a um determinado grupo configurado a partir de elementos comuns mais ou menos definidos e localizados - a um processo de carência de identidade que se define mais pela falta de uma identidade local que pela falta de uma identidade global. Em outras palavras, quando um indivíduo ou uma comunidade passa pela experiência de falta de identidade - experiência esta alimentada pela falta de certezas e referenciais fixos que emerge como conseqüência da globalização - tende a buscar a consolidação de sua identidade a partir de elementos locais, compartilhados pelo grupo, e que ao mesmo tempo, marquem a singularidade daquele perante outros grupos. Neste sentido, dois fatores concorreriam para a impossibilidade de consolidação de uma identidade global, fatores estes fundamentais para 
a formação de uma identidade: a continuidade no tempo e a diferenciação em relação aos outros.

0 primeiro fator remete, em linhas gerais, a ausência de um passado comum que possa tornar uma determinada comunidade coesa, a ponto de formar uma identidade global. Uma identidade global dependeria da criação de um senso de continuidade entre todos os povos, senso este que em última instância, dependeria de um passado comum, uma tradição comum, uma história e uma cultura comuns, de modo que "cultura comum, terra, um mito de origem, a vontade de construir um futuro comum e, quando possível, a língua, são elementos básicos que favorecem o aparecimento de uma consciência comum" (Guibernau, 1997, p. 154). Desta maneira, a formação de uma identidade que remeta a um grupo - seja nacional ou global - ou o senso de pertença a um coletivo dependeria de uma série de elementos que fossem capazes de conectar indivíduos de um determinado grupo em uma rede composta símbolos comuns, de lutas e objetivos comuns, que comportassem referenciais comuns de codificação e entendimento do mundo. A partir destas colocações, como seria possível pensar uma "consciência comum" de amplitude global?

O problema é que, conforme coloca Guibernau (1997), não há um passado comum, uma história comum, uma maneira comum de significar e compreender o mundo entre todos os povos. Ao contrário, as culturas que supostamente embasariam uma identidade global possuem histórias separadas e muitas vezes, de mútuo antagonismo, inviabilizando um processo de identificação comum, de solidariedade comum e, portanto, de formação de uma consciência comum. Desta maneira,

(...) enquanto a identidade nacional conta intensamente com um passado comum como um meio de criar solidariedade, a identidade global não tem quaisquer lembranças a utilizar para convocar a consciência de formar um grupo. (...) As culturas interpretam o mundo e criam significado, dotando assim os indivíduos de um senso de identidade. Elas são o resultado de longos processos que se estendem por gerações e se baseiam num conjunto de memórias selecionadas e partilhadas (...). (Guibernau, 1997, p. 142) 
Sendo assim, a ausência de um passado comum com o qual possam todos os povos se identificar assinala uma descontinuidade no processo de produção de uma identidade global - descontinuidade esta que permanece insolúvel, revelando-se como um empecilho fundamental para o sucesso de sua construção. Isso porque uma identidade global dependeria de uma cultura global, uma "história global", na qual todos os povos reconheceriam seu próprio passado. E ainda: tal passado seria contemplado a partir de signos e referenciais comuns, o que em última instância significaria a consolidação de uma visão única do mundo - em outros termos, uma consciência comum que, compartilhada por todos, incitaria um consenso global acerca dos fatos, do mundo, do homem e da realidade. Poderíamos pensar em um mundo onde todos fossem muçulmanos, e tudo fosse entendido a partir da lógica do Alcorão? $\mathrm{Ou}$ um mundo onde todos fossem católicos, e a própria história fosse compreendida à luz dos dogmas católicos? Seria possível uma sobrecodificação do mundo compartilhada por todos tomando por base apenas um viés sobrecodificador? E se considerássemos que, de acordo com a lógica de Guibernau, a construção de uma identidade global poderia ser possível caso a globalização constituísse por si mesma um mecanismo de construção de uma "história global", especialmente na medida em que torna as nações interdependentes, convocando-as a atuarem em um mesmo palco - o que de certa maneira denotaria uma história comum - dependendo apenas que este processo de alargasse por gerações e ganhasse tempo para se consolidar? Tal processo bastaria para a construção de "lembranças comuns", necessárias à construção de identidade?

O segundo fator mencionado pelo autor faz cair por terra tal possibilidade, na medida em que corresponde à necessidade da existência de um "outro" para a afirmação de uma identidade, na medida em que esta também se define pela constatação de sua singularidade face aos "outros". Em outras palavras, é como se a definição de identidade de um grupo se desse por um princípio de exclusão dos outros, ou seja, pela comparação com os "estrangeiros". Neste sentido, "a diferença em relação aos outros só pode ser alcançada quando há 'outros', e a hipótese de uma 'identidade global' implica, em certa medida, a negação ou substituição de identidades únicas" (Guibernau, 1997, p. 143).

Encontramos aqui uma contradição entre a formação da identidade e a continuidade das identidades, sobre a qual repousaria a suposta construção de uma identidade global. Isto ocorre uma vez que, para que haja identidade, não pode haver esta continuidade, pois a identidade 
vincula-se à alteridade, não à homogeneização. Desta forma, não é possível afirmar uma identidade se não há nada a que esta possa se contrapor. A identidade depende essencialmente da diferenciação, da singularização diante do outro, e desta maneira, é incompatível com um processo de consolidação de "identidade global", uma vez que esta supõe justamente a falta de pontos de contraposição.

A construção de uma identidade comum depende, portanto, tanto de um passado comum quanto da singularidade diante dos "outros". Se por um lado exige inclusão, na medida em que inclui o semelhante, por outro, depende da exclusão de outros grupos considerados "estrangeiros", ou seja, que não compartilham as mesmas referências diante do mundo e da realidade, a mesma língua, a mesma cultura e os mesmos objetivos. Em outras palavras, a construção de uma identidade global revela-se paradoxal pela própria definição de identidade, que não comporta o complemento "global" na medida em que se opõe ao mesmo e se revela enquanto oposição a um "outro". Desta maneira, são neutralizadas as possibilidades de construção de uma identidade global, justamente por "identidade" supor, necessariamente, diferenciação.

\section{Considerações finais}

Observa-se primeiramente neste breve estudo que todo processo causado pela globalização explicita uma tensão entre os níveis local e há uma busca de retorno ao local mediante o aumento da valorização da alteridade e das diferenças entre as culturas. Assim, "ao invés de pensar no global como 'substituindo' o local seria mais acurado pensar numa nova articulação entre 'o global' e 'o local' (Hall, 1999). Segundo, constata-se que há uma distribuição desigual do alcance da globalização em diferentes regiões do mundo. E, por fim, é evidente que a globalização é um fenômeno ocidental; é um "processo de ocidentalização" do mundo (Robbins apud Hall, 1999, p. 79). Isto é, os padrões que se difundem pelo mundo são os vigentes nas culturas ocidentais.

A dinâmica da globalização traz consigo um poderoso potencial de homogeneização cultural, especialmente em função do seu desenvolvimento tecno-científico e dos veículos de comunicação em massa de escala planetária. Neste sentido, poder-se-ia considerar a hipótese da construção gradual de uma identidade global. Entretanto, a própria globalização traz também elementos que comprometem esta homogeneização, na medida em que suscitam movimentos de 
resistência a esta dinâmica, que se expressam a partir da afirmação das identidades locais. Isto acontece especialmente em função do drástico ritmo de mudanças de paradigmas, angústia e falta de certezas e referenciais fixos para o entendimento e sobrecodificação do mundo e da realidade, decorrentes da própria globalização. 0 redimensionamento dos fluxos de pessoas trazido pela globalização também serve de balizamento para a afirmação das identidades locais, o que pode ser verificado nas recentes políticas de restrição de imigração, especialmente nos países ditos desenvolvidos.

Por outro lado, a construção de uma identidade global revela-se problemática em função da própria concepção da "identidade", na medida em que esta se define pela oposição aos "outros", ou seja, pela exclusão dos outros, e também à proporção em que exige uma "consciência comum", uma inclusão seletiva. Uma vez que a concepção "global" supõe a ausência de descontinuidade em relação aos povos, não poderia haver "outros", de modo que a inclusão de todos os povos em uma mesma identidade não poderia ser seletiva. Desta maneira, a construção de uma identidade global revela-se inviável, uma vez que remeteria a uma inclusão global que compromete o elemento de alteridade intrínseco ao conceito de identidade.

\section{Referências}

ANDERSON, B. Nação e consciência nacional. São Paulo: Editora Ática, 1989.

APPIAH, K.W. Cultura, comunidade e cidadania. In: HELLER, A. et al. A crise dos paradigmas em ciências sociais e os desafios para o século XXI. Rio de Janeiro: Editora Contraponto, 1999.

BOURDIEU, P; WACQUANT, L. A nova Bíblia do Tio Sam. La Insignia, 2001. Disponível em:

<http://www.lainsignia.org/2001/marzo/int_023.htm>. Acesso em: 7 jul. 2008.

CANCLINI, N. Consumidores e cidadãos. Rio de Janeiro: Editora da UFRJ, 1997.

DERRIDA, J. Fé e saber- as duas fontes da "religião" nos limites da simples razão. In: DERRIDA, J.; VATTIMO, G. (Orgs.) A religião: o seminário de Capri. São Paulo: Estação Liberdade, 2000. 
GUIBERNAU, M. Nacionalismos: O Estado nacional e o nacionalismo no século. XX. Rio de Janeiro: Jorge Zahar, 1997.

HALL, Stuart. A Identidade Cultural na Pós-Modernidade. Rio de Janeiro: DP\&A, 1999.

HELD, David. Democracia, o Estado-Nação e o Sistema Global. In: Lua Nova, n. 23, p. 145-194, 1991.

MANN, M. Estados nacionais na Europa e noutros continentes: diversificar, desenvolver, não morrer. In BALAKISHNAN, G. (Org.). Um Mapa da Questão Nacional. Rio de Janeiro: Contraponto, 2000.

SELLTIZ, C. et al. Métodos de pesquisa nas relações sociais. São Paulo: Herder, 1967.

VATTIMO, G. O vestígio do vestígio In: DERRIDA, J.; VATTIMO, G. (Orgs.) A religião: o seminário de Capri. São Paulo: Estação Liberdade, 2000. 